\title{
The Second International Gerontological Congress
}

\author{
By arrangement with Dr. E. V. Cowdry, president of the Second Inter- \\ national Gerontological Congress, 24 papers read at the meeting in St. Louis \\ in September are presented here in brief. These papers were selected for \\ their particular application to the field of public health and are not neces- \\ sarily representative of the entire congress. Selection was determined to \\ some extent by the availability of the papers. In abstracting, the original \\ language of the author has been retained as much as possible, and his ap- \\ proval has been obtained for the use of his work.
}

\section{The Health Insurance Plan Of Greater New York With Its Older Enrollees}

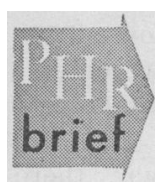

BY GEORGE BAEHR, M. D., President and Medical Director, and NEVA R. DEARDORFF, Ph. D., Director of the Division of Research and Statistics, Health Insurance Plain of Greater New York

The Health Insurance Plan of Greater New York is a voluntary, nonprofit corporation operating nnder the insurance laws of the State of New York. Every kind of medical and surgical service is available to its 282,000 subscribers. Because of the absence of age limits, a fairly large number of old people are insured under the plan. On May 31, 1951 , persons of 50 or ovier const1tuted 18 percent of the total enrollment; about 15,000 members were over 60 , and almost 6,000 were over 65 years of age.

Analysis of the utilization of physicians' services in 1948 and 1949 reveals that the rates for all HIP enrollees were identical in both years and that there was comparatively little difference in the ntilization rates for older and younger persons. About the same proportion of services was given to people both under and over 50 years in physicians' offices or in group medical centers.
Proportionately, only half as many home calls were made to older persons as to persons under 50 years. On the other hand, the proportion of physicians' visits to older persons in hospitals was about 46 percent higher than such visits to younger persons.

The 929 persons of 70 and over, both men and women, had an average of 3.4 office visits, less than onehalf a home visit, and less than three-quarters of a hospital visit in 1949. Thus, a wide margin remains for people of this age to increase their rate of utilization without creating any serious pressure on a plan like HIP.

Older persons had a slightly larger fraction of their care given by the general physician than was the case with persons under 50. HIP records show that older persons require comparatively more service from internists, general surgeons, and urologists, as would be anticipated. Older persons in the HIP population have also required more surgery, with the demand from males exceeding that of females.

Unless, in its enrollment process, it has attracted an excess of unhealthy people under the age of 50 and an excess of healthy people over that agewhich seems most unlikely-the experience of the Health Insurance Plan of Greater New York demon- strates that older persons are not excessive users of physicians' services. Enrolled in the proportions in which they occur in the general population, older people do not present problems of any magnitude or seriousness to a properly conducted plan of prepaid comprehensive medical care.

There is much to be learned about ways to improve medical care for the aging; a higher utilization rate among the aged may occur as more is learned about the possibilities of improving the health of older persons. There is no reason to believe, however, that the inclusion of the aged in a prepaid comprehensive medical care plan should materially affect the premium rates necessary for good medical care of families at various ages in life. As soon as geriatrics becomes a well-defined and generally recognized medical specialty, with sufficient representatives to undertake work in considerable volume, the HIP medical groups can integrate geriatric services in the same way as pediatric services are now incorporated in the groups' medical programs.

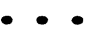

The full text of this paper is scheduled to appear in a forthcoming issue of the Journal of Gerontology under the title, "The Experience of a Health Insurance Plan with Older Enrollees." 
Involuntary Retirement and Morbidity and Mortality

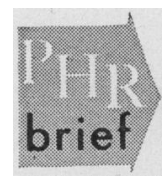

By M. L. BARRON, Ph. D., Department of Sociology and Anthropology, Cornell University

Cornell University is engaged in a 7-year longitudinal nation-wide study to test the hypothesis that involuntary, unplanned retirement based on chronological age accelerates morbidity and mortality and aggravates symptoms of senility. Differentials on morbidity and mortality will be obtained for the following groups, among others:

1. Those continuing fully active vocationally after 65 versus those fully retired.

2. Those who retire abruptly at 65 versus those who gradually retire.

3. Those retiring involuntarily versus those who retire voluntarily.

4. Those retiring without plan versus those retiring on $\dot{a}$ planned basis.

5. Those remaining at work after 65 for economic reasons versus those continuing for other reasons.

Two pilot studies in an industrial plant in Ithaca, N. Y., and a community study in Elmira were undertaken to determine the variables in old age which may affect or be affected by retirement. These studies will be used as a starting point for a 1-year nation-wide survey of a representative group of 1,000 urban people, aged 60 and over, and for a series of follow-up, in-plant studies commencing with 64-year-old people who are gainfully employed. Long-range checks will be made on the physical and mental morbidity and mortality of the latter group, and detailed information will be obtained regarding health, activities, social roles, and other factors.

To determine attitudes toward retirement, more than 500 persons representing a cross section of the population were interviewed in $\mathrm{El}$ mira. A majority indicated that the individual himself or a doctor, rather than an employer, the Government, or the union, should make the decision as to when a person should retire.

Reactions to the statement, "Workers should be encouraged to retire at 65," elicited a response of 56 percent in accord. The youngest respondents held this belief to a far greater extent than middle-aged or older ones; apparently older respondents identify themselves with the problem of retiring at 65 much more than younger respondents. In response to another question, the answer to which might indicate bias on the part of the respondent, more than three-fourths felt that older people did not demand more consideration than they have a right to expect. The analysis by age indicated, contrary to expectation, that it was not the youngest group primarily who agreed to the statement. Rather, this prejudice among older people was registered to a greater extent by respondents who were apt to be influenced by stereotyped ideas of racial or ethnic group origin. Older respondents may be more prejudiced against persons of their own age, although other questions indicated that they were less arbitrary and more individualistic about decisions for retirement. This apparent inconsistency and others may be probed further in this extensive study to determine how the aged feel and to learn more about their behavior.

\section{Something to Live For}

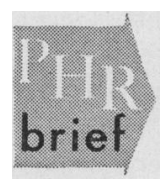

By GEORGENE E. BOWEN, Director, Philadelphia's Recreation for Older People

The Health and Welfare Council of Philadelphia asked the Philadelphia Recreation Association to undertake a program of establishment of recreation clubs to enrich the social life of many of the estimated 226,400 persons over 65 in its tricounty area. With the assistance of an advisory committee and a project director, together with 98 private and public organizations, a groundwork of understanding and cooperation was laid before actual promotion was begun.
The Recreation Association first obtained free space and facilities from settlement houses, city recreation centers, "Y's," churches, and homes for the aged. Sponsoring committees were formed to provide stability, financial backing, and volunteer help to the clubs.

Whenever possible, professional staff was used to work with older people, but mainly lay persons have acted as leaders and volunteers. At present 480 nonprofessionals are serving enthusiastically. Institutions, workshops, and conferences were held to train a total of $\mathbf{5 5 5}$ professional and nonprofessional workers.

\section{The Program and Responses}

Local sponsoring committees extended invitations to known older neighbors to participate in planned recreational activities. Although the problem of making contact with older persons is still baffling, the response of those who could be reached was immediate and enthusiastic. Today there are over 3,700 individuals gathering in 80 centers. They attend an average of 20 meetings a year.

At these "Golden Age Clubs," there is dancing, singing, playing games, painting, working at arts and crafts. Oldsters write and recite poetry, hold contests, take time for book reviews and current events, go on trips, and give dramatic programs.

The clubs are mostly neighborhood groups and vary in cultural and economic backgrounds. There are racial, cultural, and religious mixtures responsive to a single interest or to several. There are both employed and unemployed members of all economic strata. Class distinction does not exist-in a single club there is a blacksmith and a $\mathrm{Ph} . \mathrm{D}$. The age range is great, from 60 to 100 plus. In a span of 40 years two full generations may be represented.

\section{The Community}

Even though a leisure program has a powerful therapeutic force in the life of an older person, happy group association has a far-reaching beneficial effect on the community. The 
older person is no longer a burden but an asset to his locality.

The club door swings both ways, admitting the community and at the same time leading the older people into community life to which they are quick to respond.

Illnesses and resistances which characterize the older and lonely individual often miraculously disappear. There has not been a single heart attack and only one minor illness at the club meetings. Finally, the negative attitudes of older individuals dissatisfied with their community change, and those of the community change too. Prejudice disappears, and tolerance of other faiths, races, economic and cultural levels takes its place.

\section{Improving Health Care In Nursing Homes}

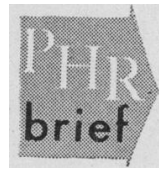

By L. E. BURNEY, M. D., Health Commissioner, and MARTHA O'MALLEY, M. D., Director, Division of Hospital and Institutional Services, Indiana State Board of Health

Institutional care of the aging is becoming increasingly important. Public health workers are interested in institutional care because of their responsibilities in problems of the aged, including chronic diseases; and because they are often required to assume functions in the inspection and approval of institutions.

Nursing homes, private and public, should provide adequate care and should maintain reasonable standards to safeguard the health and promote the welfare of their residents, particularly elderly people. One of the measures to assure standards is through the licensure and approval of institutions. There has been a definite trend in this country for States to enact laws requiring licensure of hospitals and nursing homes. This trend was stimulated by the enactment of the Federal Hospital Survey and Construction Act and by the recent amendments to the Social Security Act.

In Indiana, considerable study was given to the development of a sound program for the licensing and approval of a number of institutions. The responsibilities of the State Board of Health are in the field of health and environmental sanitation. It works closely with the Department of Public Welfare, which administers the program of approval of county homes for assistance cases, and with other State agencies having similar responsibilities.

Most operators of institutions are sincere and well-intentioned, but they sometimes fail because of lack of awareness or understanding of the problems or because of inability to cope with the situation. Therefore, the program should be one of education and assistance, rather than of compulsion. Police methods should be resorted to only when all other methods fail. Standards and regulations should be in the form of basic principles rather than an outline of specific details. The application of principles allows for flexibility and encourages individual variation to meet particular situations.

There are certain common basic problems which have appeared in the work with county and nursing homes in Indiana. These are: (1) lack of a definite plan for care of chronic disease patients in different age groups; (2) lack of community understanding and support; (3) lack of a representative group of citizens to work with operators of homes on policies and programs for care; (4) need for administrators to understand program planning and the needs of chronic disease patients; (5) need for supervision of nursing care by qualified registered nurses; (6) need for well-balanced diet and meal planning for the aged and chronically ill patients; (7) almost complete absence of physiotherapy services; (8) the little effort made to keep the persons in county or nursing homes occupied; (9) the limited amount of medical care now provided, which is usually on the basis of individual need rather than on a definite plan of supervision and care; and (10) need to improve the physical structure to provide good environmental sanitation and to modernize utilities and service facilities.
A comprehensive evaluation of present health needs of older people and a plan based on their needs should be made. The plan should include an allocation of public and private nursing home beds based on realistic criteria of need and on the proposed over-all program. This plan should be developed before licensing agencies proceed with regulations, since requirements should be directed to the program of patient care the institution is expected to carry out. A model set of regulations and standards for public and private nursing homes should also be developed to serve as a guide to States and counties in working out their own requirements. Personnel specifications should be established to include experience, training, and personal qualifications of the staffs of nursing and county homes. Finally, special training programs should be inaugurated for the licensing of agency personnel.

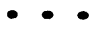

The full text of this paper is scheduled to appear in a forthcoming issue of Geriatrics.

\section{Nutrition, Senescence, And Rejuvenescence}

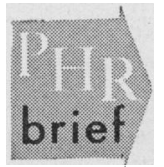

By A. J. CARLSON, Ph. D., and F. HOELZEL, Ph. D., Department of Physiology, University of Chicago

More than 35 years ago, the senior author found that a 5-day fast, undertaken to study hunger, produced highly beneficial physical and mental after-effects. Marked general improvement lasting at least 6 months was experienced by Hoelzel following a 26-day fast in 1913, and similar improvement was experienced in 1917 following a 15-day fast, despite the development of nutritional edema.

These experiences seemed to support the findings of Child in experiments with planaria-that starving had some rejuvenating effect (Senescence and Rejurenescence, University of Chicago Press, 1915). Child regarded the rejuvenation of planaria by starvation to involve an 
increase in the rate of metaboliem. Studies on three dogs and seven men confirmed this view although one study on Hoelzel did not.

In 1928 , it was found that mental performance of three subjects was increased above the prefasting level for some time after fasting.

Prolonged fasting evidently produces the most striking effects and after-ffects within the shortest time. Hoelzel found that a general improvement following intermittent fasting seemed equal to that following less prolonged fasts. In 1040, however, he found that, with aging, the ability to do light work while fasting one or two days evidently decreased, and the ability to become nutritionally rehabilitated rapidly after short fasts also decreased.

In a study on rats it was found that fasting 1 day in 3 was about the optimum for prolonging the life span without significantly impairing growth. Life span of rats fed a concentrated or rich diet ad libitum was shortened and fertility impaired. and it was impossible to maintain a population of 50 rats after the third generation. Ten generations were obtained from the most fertile rats before reproduction failed completely, but this represented a total breeding span approximately no longer than the single life span of some of McCay's long-lived rats.

An impairment of reproduction can be considered as representing an impairment of the periodic rejurenation which normally prevents a cumulative aging of the species. The observations of Rudzinska on Tokophyra infusionum have shown that overeating can impair reproduction and shorten the life span of lower organisms, and the authors believe that their findings on rats apply also to man.

Fasting or prolonged food restriction, if not carried too far, can evidently produce conditions in which the organism can at least temporarily utilize larger amounts of food than can be utilized at the same age by a continuously fed organism. On a purely physical basis, nothing may be gained, as the decrease in energy production during food restriction may only be balanced by the increased energy produetion during nutritional rehabilitation. However, improved mental functioning during nutritional rehabilitation may outweigh depressed functioning during food restriction.

It is possible that the striking beneficial after-effects of prolonged fasting may be due to a hypertrophy of the adrenals or that the nonessential tissues used up in starvation may include abnormal accumalations of some intermediary product of metabolism.

\section{Illness Among Older People in Hagerstown}

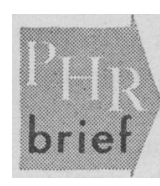

By A. Ciocco, M. D., Graduate School of Public Health, University of Pittsburgh, and P. LAWRENCE, M. D., Division of Public Health Methods, Public Health Service

This paper is an analysis of data gathered in two house-to-house surveys, conducted 20 years apart, 1923 and 1943, in Hagerstown, Md. The analysis is concerned with the occurrence of chronic lllness and death in the 20-year interval and with the relationships involved. The longitudinal type of study, 1.e., a study based on repeated observathons on the same group of persons over a period of time, is a valuable method of answering some of the important questions related to an aging population, particularly sickness and disability trends.

From findings in the National Health Survey and the Hagerstown survey of 1943, it is estimated that at age 65 about 40 percent of the population have some chronic disease or major impairment. Although this measure of prevalence is valuable, it does not measure change-the relationship of current health status to past exposure to disease. For this information, it is necessary to obtain data on incidence, which, for the chronic diseases, require the longitudinal approach; this permits us to observe the frequency of change in a group with known characteristics by fol- lowing the same individual over a span of years.

Analysis of the data shows that of persons 40 to 50 sears of age in 1923, less than 50 percent were alive and without chronic illness in 1048, and only slightly more than 20 percent of those who were 50 to 60 years old in 1923 were alive and well in 1943. Previous chronic illness has an unfavorable effect on future health status. A substantial proportion of the persons who are ill at 65 have had the same or another chronic illness for at least 20 sears. This leads to the conclusion that, if disease is to be prevented in the man of 65 , observations must be begun and action taken before he is $\mathbf{4 5}$.

Approximately 100 of every 1,000 persons who are well at age 45 will require, during the next 5 years, medical attention for the onset of a chronic disease or a major impairment. Some will require periodic medical treatment, but a few will need almost constant medical care of some kind until they die. Nearly 25 percent of those who are well at 60 will develop, within 5 years, a chronic ailment for which they will probably require medical care and, in many cases, care of a continuing nature.

\section{Management of the Older Employee With Medical Problems}

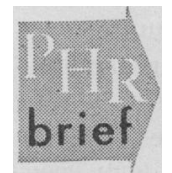

By RUfUs B. CRAIN, M. D., M. P. H., Medical Director, Kodak Office and Camera Works, Eastman Kodak Co., Rochester, N. Y.

The Eastman Kodak Company emphasizes the value of selective job placement and follow-up of workers with physical or mental disabilities. Job descriptions now include information concerning physical requirements and job environment, and the total information is made available to the medical department. Thus, it is possible to match physical capacitles with work requirements. This system has disclosed a number of jobs not previously recognized as 
suitable for the older or disabled worker.

The company's experience with accident and sickness rates reveals that age is a factor contributing significantly to the sickness-disability rate. Men 40 years of age and over lost nearly two and three-quarters times as many days per person as those under 40 . Likewise, older women (40 and over) lost nearly one and three-quarters times as many days per person as younger women. Bowever, age is not a problem as far as industrial injuries are concerned. On the basis of the number of lost-time injuries per 1,000 employees, the company has found that the rate of disabling injuries is roughly the same in all age groups.

The companx's nutrition department carries on a general educathonal program for workers, as well as counseling for managers of cafeterias and service dining rooms and indiridual counseling with employees. Many older people referred because of such conditions as overweight or underweight, osteoarthritis, hypertension, etc., have been greatly benefited by proper diets.

As a result of a growing need for attention to personality disorders and problems of adjustment, a psychintrist was aclded to the staff of the medical department on a parttime basis. The preventive aspects of the psychiatric program are stressed, consistent with the company's conriction that continuing education in the psychological and psychlatric approach to employee problems is necessary for all levels of management. Psychosomatic disturbances, particularly the anxiety type of neurosis, account for the majority of mental disorders found in industry. On the basis of the experience of the Eastman Kodak Company, age does not appear to have any striking effect on the type of personality disorder encountered.

Experience with employees having cardiorascular disease indicates that, with proper placement and follow-up, persons with various impairments may be satisfactorily em. ployed.

Normal retirement, with eligibility for benefits commensurate with length of service, occurs at age 65 .
However, most people may continue to work for Eastman Kodak as long as their health and ability to do their jobs permit. In the past few years, the company has instituted educational programs on preparation for retirement and on activities after retirement.

$$
\text { - - }
$$

The full text of this paper is scheduled to appear in a forthcoming is sue of the Archives of Industrial $H y$ giene and Occupational Medicine.

\section{Clinical Problems \\ In Gerontological Rehabilitation}

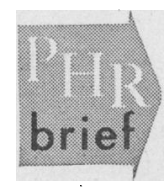

By M. M. DASCO, M. D.; Service of Physical Medicine and Rehabilitation, Now York City Department of Hospitals (Goldwater Memorial Hospitall

Rehabilitation of the aged aims to restore such persons to their fullest physical, mental, social, and economic usefulness. This definition clearly shows that the problem is more than medical and the aid of all ancillary specialists has to be enlisted to rehabilitate an aged person. In spite of the erer-growing scope of specialization, there are a great number of morbid conditions which always happen to be "outside the field" of any specialist. It is the duty of the rehabllitation specialist to handle these heretofore neglected conditions and bring about as full a restoration as the situation permits. Rehabilitation activities of elderly persons could be arbitrarily classifled into three groups: (1) restoration of the obviously handicapped aged (such as those suffering from hemiplegia, arthritis, fractures, and neuromuscular diseases) ; (2) rehabilitation of those who are chronically Ill but show no obvious signs of disability (patients with chronic cardiac and pulmonary diseases); and (3) restoration of the elderly person who has no manlfestation of a specific disease but whose physical fitness is impaired.

With the basic principle in mind that a mere geriatric clinic is insufficient for the successful rehabili- tation of an elderly patient, a gerontological guidance clinic is being planned, which will offer complete rehabilitation in terms of the definition given above.

\section{Services Offered}

The service will consist of three main sections, the first of which will offer complete medical and surgical services, including a complete physical rehabilitation service and nutritional consultation. The second will be the psychosocial service and will include a psychologist and social workers who will work in close cooperation with the psychiatrist and the rest of the members of the medical-surgical section. A domestic relations counselor will help to adjust the aged patient and his environment to each other and thereby eliminate the frequently observed friction between two or often three generations who are forced to live together. This section will also have housing and legal consultants to take care of the special problems arising in these fields.

The third will be the rocational and employment section, whlch will consist of a testing psychologist and a vocational and employment counselor. This section will advise on vocational training and retraining and will attempt to obtain employment for the successfully rehabilitated elderly patient.

\section{Specialist Participation}

Joint conferences with the participation of all medical and nonmedical specialists will make it possible to discuss all facets of the elderly patients' complex problems and will enable us to render a more efficient and realistic service to these people.

Such a service will not only be useful for the elderly sick of the community, but it will also provide essential counseling service for industry in helping them to establish a sounder retirement policy by replacing the archaic chronological system with one based on the worker's physical and mental status and his ability to perform.

$$
\text { - - }
$$

The full text of this paper is scheduled to appear in a forthcoming issue of Geriatrics. 


\section{The Young Candidate for Coronary Heart Disease}

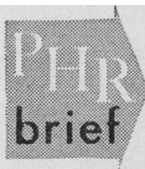

By M. M. GertLeR, M. D., Department of Medicine, Columbia University College of Physicians and Surgeons

Modern diagnostic methods have achieved a great deal in the diagnosis of the acute or subacute phase of coronary heart disease which terminates in myocardial infarction. The increasing death toll from coronary heart disease suggests that another form of approach to this problem be studied, namely, the prevention of coronary heart disease. In a recent study of 100 individuals who had experienced myocardial infarction prior to the age of 40 , certain leads were uncovered which may help in recognizing the individual who is prone to coronary heart disease. One hundred and forty-six normal individuals of roughly the same physique, occupation, and ethnic origin were used as controls.

It is noteworthy that 42 men in the coronary heart disease group held managerial positions; 11 were professional individuals; 7 were semiprofessional individuals; 4 were skilled workers; 30 were semiskilled workers; and 3 were unskilled workers.

On the basis of the study, certain phenotypic expressions were selected which are thought to represent the coronary heart disease profile pattern:

Hereditary History. Presence of coronary heart disease in any sibling or in either parent at an early age; history of metabolic diseases, arthritis; history of hereditary hyperuricemia and hypercholesterolemia.

Psychological History. Strong, goal-directed drives, usually with accomplishment; aggressive pattern not an outstanding feature; high athletic rating in contact sports; "less masculinity" in absolute values, as revealed by Terman-Miles test.

Anthropometry and Somatotype. Dominant mesomorphy; secondary endomorphy ; decreased linear measurement (on the average the coro- nary heart disease group was 2 inches shorter than the average height of the control group); increased horizontal measurements; no evidence of an abnormal increase in weight.

Biochemistry. Serum cholesterol elevated; serum uric acid elevated; serum lipid phosphorus slightly elevated; serum cholesterol/serum lipid phosphorus ratio increased; "CUP" index (cholesterol $x$ uric acid/lipid phosphorus) increased; reduced intensity of saliva to low EMF (electromotive force) values; urinary 17-ketosteroid excretion, low normal; basal metabolic rate, low normal.

Clinical History. Usually no signs of heart disease prior to the coronary episode.

The question may be asked, "What may one do once preselection of the coronary-prone male is made?" It has been demonstrated that the relationship of the total cholesterol/lipid phosphorus ratio may reflect the stability of the cholesterol in the serum. The degree of intimal permeability to cholesterol may be a very important factor, for one could theoretically conceive of a condition whereby the coronary intima is impermeable to cholesterol or to its products. In view of this, preventive therapy would consist in re-establishing the total serum cholesterol/serum lipid phosphorus ratio and decreasing the permeability of the intima in the coronary arteries.

The full text of this paper was published in The Journal of the American Medical Association, 147: 621-625, October 13, 1951.

\section{An Adequate Program Of Medical Care For Elderly People}

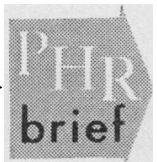

By FRANZ GOLDMANN, M. D., Associate Professor of Medical Care, Harvard University School of Public Health

There is wide agreement about the need for a broad and well-balanced medical care program to meet the requirements of the aged at the least cost compatible with adequate service. The problem common to civilized countries is the elimination of obsolete practices and policies, the improvement of services which have met the test of time, and the filling of gaps in accordance with current scientific knowledge and social philosophy.

\section{Over-all Plan}

Health needs of older people are numerous and complex and in some respects quite different from those of younger people. Generally, the amount and types of services needed, as well as their duration, substantially exceed those for younger groups. This situation arises from five factors: frequent occurrence; severity and long duration of physical and mental diseases; exacerbation of conditions originating earlier in life; serious course of some acute diseases in old age; psychological, social, and economic effect of illness in elderly people; and the social and economic setting within which elderly people live in many countries, particularly those in advanced stages of industrialization and urbanization.

\section{Components}

The program must include services of general physicians and specialists, dentists, pharmacists, social workers, professional and practical nurses, homemakers and housekeeping aides, and others possessing special skills. It must include a supply of prescribed drugs and appliances.

The essential physical facilities include diagnostic clinics, general and special hospitals designed to serve patients with long-term illnesses, nursing units or complete hospital sections in homes for the aged, and boarding or nursing homes under medical supervision. The diagnostic clinic is the heart of a forwardlooking program.

As important as physical facilities for the sick is low-rent housing for the displaced elderly person, with provision for health supervision. Efforts should be made to maintain older people in their own homes. Organized housing projects should 
replace huge institutions. Within large communities, housing projects should be equipped with small infirmaries and nursing service to provide care at home.

\section{Organization of Payment}

Orderly arrangements for financing programs are as important as their creation. Adequate physical facilities are expensive; the task of raising necessary capital may be beyond the power of any single group, voluntary agency, or political unit. Cooperation is the answer. General tax funds to supplement resources of voluntary organizations have been provided in some countries. Operating costs of a medical care program should be met through insurance, general tax funds, or a combination of both, with emphasis on self-help. An insurance system which will meet the needs of elderly persons must include medical care and disability and old-age benefits. To the extent that insurance funds are spent on health care and income maintenance, the need for public assistance declines.

To be effective and economical, a program for the elderly must assure comprehensiveness, continuity, and consistency of qualitatively adequate medical care through the stages of health, acute sickness, convalescence, and long-term illness. Health of the older person must be maintained, diseases associated with higher age prevented, and illness must be met through early diagnosis and prompt treatment. The program must cover service at the home, the offices of the doctor and the dentist, the diagnostic and treatment clinic, the hospital, and the institution designed for long-term care. Emphasis on institutional care, neglecting home and office care, is insufficient, unwise, and costly.

\section{Specifications}

Success of a health-service program for elderly people depends on progress in scientific medicine, especially gerontology; education of all people in the principles of healthful living; and the establishment and improvement of general programs of medical care for all age groups. Otherwise, such a program will still be useful to the individual but extremely costly to the community.

Furthermore, income must be provided to enable elderly persons to maintain a decent standard of living. Also, such a program requires careful preparation, including arrangements for both systematic organization of service and for methodical payment. Execution by stages over several years may be necessary.

\section{Organization of Service}

There must be systematic organization of the services of professional and auxiliary personnel, of clinics, hospitals, and related facilities, and use of definite methods to compensate service personnel. Teamwork is essential because of the variety of health personnel and institutions involved. Differentiation of service and division of labor will go far to make the total program efficient and economical, reduce personnel shortages, and free expensive hospital beds. Organization and teamwork mean determining the functions to be performed by the various professions and use of a referral system among institutions.

The full text of this paper is scheduled to appear in a forthcoming issue of Geriatrics.

\section{Older People Live In Instifutions}

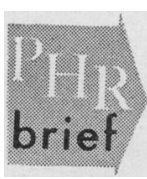

BY BENJAMIN L. GROSSMAN, Executive Director, Drexel Home, Chicago

Institutional housing for older people includes the nursing home, both profit-making and nonprofit; homes for the aged, both public and private; county homes; infirmaries and hospitals for the infirm and chronically ill ; and hospitals for the mentally ill. Older people enter institutions because they have a chronic illness, because of physical disability, because of personality difficulties, and because they are not wanted or needed in the family.
An institution for older people should be a therapeutic and rehabilitative agency. The approach should be individualized and founded upon a knowledge of human behavior and motivations. This implies a 1 recognition and an acceptance of the fundamental principle that an older person's response to his problems will be like that of any adult.

When people who have grown older live in an institution, they have a right to good medical care, comfort, protection, privacy, freedom of speech and action, good nutritious food, proper social and recreational life, clean shelter, respect for their possessions, and the right to worship as they desire.

Licensing laws can help to improve and to insure the welfare of the people who live in institutions, and every State should have such laws. However, a law alone will not solve all the problems; it must be one element in a broad, constructive, community program. Laws need to be supplemented with methods for improving the low quality of care now provided in many institutions throughout the country.

A licensing law should be brief, simple, and clear-cut. In general, it should deal with broad objectives and leave detailed requirements for administrative rules and regulations.

Standards of good care and adequate services are vitally important. Administrators and operators of various institutions for the aged must be encouraged to provide the care which will result in maximum benefit for the people who live in the institutions. In its broadest sense, thus, the care of older people is a community problem.

\section{Cost of Chronic Illness}

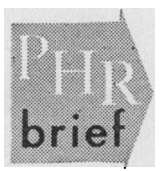

By RAYMOND A. HILLIARD, Ph. B., LL. B., Executive Director, Welfare Council of New York City

Despite new medical discoveriesand there are certainly great advances in sight-there is much to be done in preventing chronic illness. It is now possible to say that at least 
50 percent of chronic illness can be arrested if treated early enough. Moreover, rehabilitation can work new miracles.

In the social sciences, however, there is little progress to report. Society has relegated increasing numbers of old people to an economic and social scrap heap, with increasing evidence of discrimination against employment of older people. Handicaps of age have become as real as many of the physical handicaps, even though there is no connection between them.

\section{Prevention Stressed}

The most important approach in both medical and social spheres is for understanding and prevention rather than treatment. The social sclences should emulate the medical sciences in their conquest of chronic diseases, to insure equal success in attacking the social handicap of increased age.

Costs of chronic illness. are both direct and indirect. The former are confined to medical and related services for nursing and hospital care. Indirect costs include employment loss not only by the chronic inralid but by those who must care for him. There are also social losses such as the "tyranny" imposed on the household in which the chronic invalid lives.

Perhaps as many as 25 million people have some chronic disease, and nearly 1 million deaths and 1 billion days of disability a year can be ascribed to such illnesses. It is estimated that between 1.25 and $\mathbf{1 . 5}$ percent of the total population have chronic lliness of prolonged duration, requiring the help of others and progressing to a need for constant attention and special service.

Chronic illness is not a problem of the aged alone. It strikes devastatingly in the middle years.

Chronic invalidism is the greatest single factor, other than great economic depression, in forcing people onto public assistance rolls. In a typical Illinois county, almost onefourth of all public assistance recipients were chronic invalids. Of the aged, well over one-third were chronic invalids. In addition to economic and physical care prob- lems, chronic illness creates other problems: children or parents may have to give up employment in order to care for the sick ; physical or emotional impairment of family members caring for the invalid may result in affecting others, in a "chain reaction."

Although the flelds of geriatrics (diseases of the aged) and gerontology (the aging process) perhaps represent most-neglected areas of medical and social sciences, there is a present awareness of the great' significance of the aging problem. Attitudes toward chronic invalidism need thorough revision. Too often there is a sense of shame, minimizing knowledge of the problem and hindering planning. Such an attitude is intensified by the fact that there are few adequate facilities outside the home, so that institutional care for un invalid is regarded as "unnatural" or "heartless."

This tragic situation can be corrected and these costs of chronic illnesses may be arerted. Costs will double unless research, treatment, and rehabilitation are intensified.

Apart from functional disorders, old people deteriorate because they are not wanted-society has not planned for their utilization. Deterioration is hastened and promoted in the face of lonely years of unrelieved idleness. Community planning may provide some of the answers. In New York City, for instance, day centers provide a place where older people may gather. They rejoin society, become a part of things, and feel wanted. New York's Hodson Center has enrolled over 1,000 old people as members. Only one has entered a mental institution, although statistics indicate that on an average 40 would have been admitted. Here is prevention at little cost and one answer to the overcrowding of our mental institu. tions. Many more centers are needed, but government and private philanthropy cannot afford to provide them. The answer may be found in every neighborhood and in every community which has churches and synagogues. They have facilities and their members can raise funds and supply volunteer staffs. A precaution must be taken-churches should initiate programs only with competent, trained, social work direction. And, as is done in child care, government can provide consultation services through welfare or health departments.

\section{Exploring Housing Needs of the Aging}

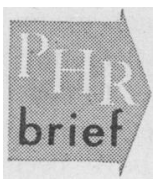

BY BLEEKER MARQUETTE, A. B., Executive Secretary, the Public Health Federation, Cincinnati.

The best available estimates indicate that probably about 95 percent of people over 65 years of age live in individual households, either alone or with others. Moreover, that is the way they seem to want to continue. The major problem in housing for older people is an adequate supply of acceptable housing units adapted to their ability to pay. There doesn't seem' much likelihood of meeting the need effectively unless the over-all housing situation is improved.

The principal housing problems for older people occur among middleand low-income groups. The solution for middle-income older people would seem to be the same as that for middle-income families generally, namely, more housing at moderate prices. For low-income famllies, where the situation is most serious and where housing is substandard and inadequate, some kind of subsidized housing is needed. If the aging are to benefit, a clarification of public housing policy is essential. More dwelling units must be provided for two-person and oneperson families, and the single older person, as well as older couples, must be made eligible and welcome. This must be done, not at the expense of younger families, whose needs are, if anything, greater than those of the aging, but through the addition of more small units suited to older people.

Although many older people are able to make good adjustments in various types of living arrangements, most of them prefer to stay 
in their own homes, even through mild illness. In order to enable them to do so, certain auxiliary aids should be made available to them. Among these are visiting housekeepers to help with housework, home medical and nursing care, and the services of social case workers. Some older people, particularly those who are single and are inclined to be lonely when living by themselves, want congregate living if they are not too greatly regimented. More such homes of the modern type geared to older people's wants and allowing a maximum amount of freedom of activity are in demand.

It is questionable whether housing units need to be specifically designed and reserved for older people. Some of the special housing needs of older people are special provisions for safety, doors wide enough for a wheel chair, elimination of stair climbing, heating and ventilating subject to control by the occupant, absence of excessive noise, and accessibility to transportation, stores, libraries, and other facilities. Rather than thinking in terms of promoting the development of housing units to be set aside for older people, a more practical approach might be to establish standards for features in housing that are desirable for older persons and also for other small households. Then a concerted effort might be made: (1) to persuade private builders to adhere to these principles in designing smaller units, and local housing authorities to incorporate them in their planning, and (2) to induce both groups to provide more of them.

\section{Public and Private Community Planning For the Aged}

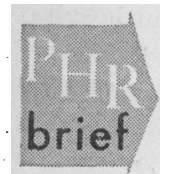

BY HENRY L. MCCARTHY, Commissioner, New York City Department of Welfare

The relationship between public and private welfare agencies in planning and executing programs for the aged requires re-examination in the light of modern trends. Until recently, most assistance, especially institutional care, was provided by private agencies. Conditions of city and county homes and public mental institutions were for the most part bad.

Programs for the aged can no longer be thought of in terms of institutional care only. First, the question of employment of the older person has to be considered. Then, because of the rapid increase in urban population, housing for older people must be developed. Finally, there are more older people; better medical diagnosis and treatment hate brought better health for more years of life than ever before.

\section{Economic Status}

The economic status of older people is fundamental to cooperation be tween public and private agencies. At best there are 20 percent of those 65 years of age or over who have sufficient income and health and are otherwise situated so that they have no need for welfare agencies. At the other extreme, purely economic, 22.4 percent of thase 65 jears of age and over must rely on public old age assistance. In New York City, those on public assistance rolls comprise 10.6 percent of all those 6.5 years of age and over. The present trend is toward a greater percentage of the aged finding support through public assistance and for greater liberalization of these programs.

Other services are available to those receiving assistance payments. In New York City, medical care, nursing, and housekeeping services in the home, convalescent home and institutional care, and social services are provided. The completeness of services available to recipients of public aid underlines the fact that those who are not quite eligible for assistance are much worse off than those who are on the program. Their needs are often great but they must look to private agencies.

Complete cooperation between public and private groups may reduce the public assistance lists. In the field of rehabilitation, public agencies should refer the handicapped to private organizations.

In addition to those who are re- ceiving assistance or are entirely independent, perhaps another 25 percent of the older people are supported by their children. There are also 1.7 million benefictaries under the Federal Old Age and Survivors' Insurance program. Other programs, such as the Railroad Retirement Plan and, of great significance, private pension plans, also provide support. We may be approaching a solution of economic problems of the aged, but money is not all that is involved.

\section{Social Status}

The idleness and isolation to which older people are often consigned bring many to the brink of despair. Mental and nervous breakdowns and possible commitments to mental institutions result. In New York, day care centers for the aged, sponsored by private agencies and the department of welfare, provide an opportunity for older people to develop a satisfactory social life of their own. They require less medical care and lead otherwise normal lives.

Institutions for the aged, both public and private, are improving, changing from mere custodial centers to centers offering many programs and activities even for the chronic invalids. We are learning to discard the term "incurable." The home for the aged maintains apartments, finds foster homes and furnished rooms, correlates its work with health, visiting nurse and housekeeping services, and makes referrals for hospital care.

By working with public organizations, private agency programs may be vastly extended. Continuation of public assistance payments helps to support the private agency. None of the private agencies could maintain their programs without public as sistance payments to those who are destitute.

In New York, a Mayor's Advisory Committee for the Aged, composed of leaders in both private and public welfare fields, is concerned with the problems of the aged generally. This correlation on the basis of equality and mutuality in planning for the aged is an outstanding example of the interrelatiouship of both for the benefit of all. 


\section{Hospital and Institutional Care}

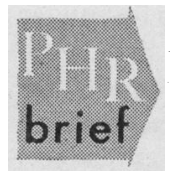

By A. P. MERRILL, M. D. Superintendent, St. Barnabas Hospital, New York City

Among our most effective tools for care of the geriatric patient in modern society are hospitals and related institutions. However, they have not been advantageously employed compared with their utilization in acute medical conditions. The hospital can play an ever-progressive role in public health programs by being the center for health and medical care activities concerned with the chronic disease patient.

A reduction in chronic disease would greatly lighten the economic burden in caring for an aging population, since invalidism and disability increase progressively with age. However, it is estimated that by 1980 there will be about 40 million persons with chronic illness in the Nation, a third of whom may need adequate hospital care for diagnosis, treatment, or rehabilitation.

There are three major categories of geriatric patients: (1) the shortterm patient with an illness of under 6 months' duration, who ordinarily is subject to rapid rehabilitation, and who is frequently cared for by the general hospital; (2) the long-term patient requiring care for from 6 months to 2 to 3 years, who may make a much slower recovery and who is frequently found in the specialized hospital for chronic diseases; and (3) those patients with extreme handicaps and severe impairments of health for whom the outlook is less encouraging for complete recovery but who can nevertheless make improvements. These patients are generally found in chronic disease hospitals, in welfare institutions, custodial and nursing homes, and even homes for the aged.

In planning community programs for care of these three types of patients, two fundamental principles should be recognized. The first applies to the dynamic concept of the medical state of patients with chronic disease, who are either getting well or getting worse. Thus, there is a continual interchange among these three basic categories, and a comprehensive community program should provide for appropriate facilities which would enable patients to be transferred to those accommodations most suitable to their medical conditions. The second principle is that medical care for all categories of the chronically ill should be integrated and continuous, so that a person changing from one dynamic medical state to another is not penalized for lack of adequate medical and nursing care.

\section{Chronic Disease Facilities}

There are at present about 127,500 hospital beds for the chronically ill. In addition, it is estimated that a quarter of a million geriatric patients are housed in many other types of institutions, including nursing homes, welfare institutions, and the like, where the quality of medical care may not always be adequate and where the program may fail to meet modern standards. It is estimated that during the next $\mathbf{1 5}$ to 20 years some 300,000 beds will be needed for general categories of chronic illness, about 175,000 of these for active medical care and $\mathbf{1 2 5 , 0 0 0}$ for related care.

Aging and chronic disease are not synonymous, but there is a large interrelation which should be considered. Moreover, aging complicates chronic illness. The care of the geriatric patient in modern society requires the development of extensive community and institutional resources under both governmental and voluntary auspices; integration and control programs should be established through both types of agencies. Every State health department should have a division of geriatrics or chronic disease control.

The chronic disease hospital should be a center for professional and public education, prevention, and research, as well as for new advances in care and treatment. It should also be the center for the training of professional and auxiliary personnel and for development of administrative leadership.
A community of 100,000 people would require a 450-bed chronic disease facility-200 beds for active medical care and 250 beds for the custodial domiciliary, or infirm aged. Such a facility could be operated independently, in a physical sense, or integrated with an existing general hospital. There is not just one pattern of hospital care for the geriatric and chronic disease patient that will fit every conceivable situation. Each community should study its individual needs and act accordingly.

Methods must be found for financing the cost of hospital and institutional care for the chronically ill and infirm aged. Voluntary and private insurance programs should be broadened and extended to cover long periods of sickness and disability, which currently are excluded. Amendments to the Social Security Act are feasible, as well as medical assistance programs from Federal, State, and community sources. The economic aspects of the problem are momentous and upon their solution largely depends the satisfactory outcome of all health, medical, and related problems.

\section{Health Services for the Aging in Saskatchewan}

BY FREDERICK D. MOTT, M. D., Health Department of Saskatchewan, Canada, LEONARD S. ROSENFELD, M. D., Division of Public Health Methods, Public Health Service, and MALCOLM G. TAYLOR, University of Toronto

In the last 7 years the Province of Saskatchewan has developed a wide range of health services, including government-sponsored hospital care, tax-supported care of cancer cases, comprehensive medical and hospital services for recipients of public assistance, compulsory medical care insurance in the Swift Current health region, a grant-in-aid program for hospital construction, and an air ambulance service.

Health services for the aging in Saskatchewan have developed as part of the general community pro- 
gram. Nevertheless, of all groups in the community, the aging benefit most from the values of organized health services. For the aging, the need for medical services rises sharply at a time in life when income either remains fixed or diminishes.

Three programs which are of significance to the aging are the hospital services plan, medical services for social assistance recipients, and the Swift Current health insurance program. During the 4 years of operation of the hospital plan there has been a substantial increase in the utilization of hospital services. This increase was most marked in the age group 65 and over. In 1950 the average length of stay in hospitals for the group aged 65 and over was 21.6 days compared with 9.2 days for the people under that age. This is a result of numerous factors, including differences in the causes of illness, differences in recuperative powers, and changes in mobility and social environment among older people.

Analysis of the Swift Current health region compulsory insurance program reveals that those over 65 years of age receive a much greater volume of care than those under 65 . This is true for office and home care, as well as for hospital care.

The health programs in Saskatchewan are characterized by the reduction of economic barriers to necessary health services, and by a minimum of restrictions. With the removal of economic barriers to care of the aged, it is possible to measure the force of various medical and social factors which influence the demand for and the provision of medical services. It is obvious that aging, with its physical, social, and psychological concomitants, contributes toward a high demand for health services.

The aging, as a group, provide a rich field for the study of medical sociology, not because of problems peculiar to this group, but because many of the physical, psychological, and social ills common to all ages converge toward the end of life, creating some of the most difficult problems in organizing an effective system of health services.

\section{The Normal Precordial Electrocardiogram In the Aged}

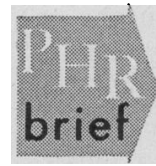

By O. OlBRICH, M. D. Ph. D., and E. WOODFORDWILLIAMS, M. D., General Hospital, Sunderland, England

This study is concerned with electrocardiographic changes caused by age and with deviations from the accepted norm of the younger population. Five hundred in- and outpatients admitted during the period of 4 months to the geriatric unit of the Sunderland Group of Hospitals were electrocardiographed and their electrocardiograms analyzed. Fifty young normal subjects (aged 20-40) were investigated under the same basic conditions.

The results showed that in the young the vertical and semivertical positions of the heart predominate, whereas in the aged the horizontal and semihorizontal positions are more common. In the precordial and unipolar extremity leads, $\mathbf{P}$ waves are smaller in amplitude in the aged than in the young controls, and with advancing years the percentage of absent $P$ waves increases.

With advancing years more $Q$ waves are found in the precordial lead V3. The amplitudes of the $\mathbf{R}$ and $\mathbf{S}$ waves do not differ, nor do they differ significantly in the aged as compared with the young controls. The sum of $R$ in $V 5$ and $S$ in V1 representing the left ventricular potential and the sum of $R$ in V1 and $S$ in V5 representing the right ventricular potential do not change with advancing years. The QRS duration is longer in the aged than in the young. The ventricular activation time differs slightly in the aged when compared with the young controls. RS-T depressions in the left precordial leads, especially in V4 and V5, were found in $\mathbf{1 1}$ percent of the cases. The amplitudes of the $T$ waves decrease with advancing years. The transitional zone depends on the rotation of the heart around its three axes. The $P R$ interval does not change with advancing years and the $\mathrm{QT}$ ratio increases with age, but not above the upper limit of the normal.

\section{Electrocardiographic Patterns}

The heart, fixed in the thoracic cavity by the great vessels at its base and supported in this position by the lungs and diaphragm, might rotate, displaced, with the apex forwards or backwards. In the aged, additional factors play an important role with regard to the position of the heart: alteration of shape of thoracic cavity, senile atrophic emphysema, the lower position of the diaphragm, and the tortuosity and elongation of the aorta.

Thus, spatial changes could be responsible for certain electrocardiographic patterns encountered in the aged. As evidence for this, we have taken tracings with the patient in the supine and recumbent positions and by rotating his body at different angles were able to produce $\mathbf{Q}$ waves, shift of the transitional zone, and increase or decrease of the amplitudes of the $R$ and $S$ waves in both unipolar and precordial extremity leads.

From the above we draw the conclusion that the decrease or increase of the amplitudes of the different waves and deflections is not due to change of action current caused by age but simply expresses the distance of the exploring electrode from the heart. We do believe that the action current does not change with advancing years.

The full text of this paper is scheduled to appear in a forthcoming issue of the Journal of Gerontology.

\section{Health Status and Health Requirements of An Aging Population}

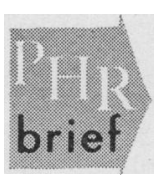

By GEORGE ST.J. PERROTT, M. A., MARCUS S. GOLDSTEIN, Ph. D., and SELWYN D. COLlINS, Ph. D., Division of Public Health Methods, Public Health Service

The number of persons aged 65 and over is increasing rapidly, both in absolute numbers and in relation to the total population. This paper reviews the health status of this 
group, measured by the prevalence of illness and the receipt of medical care, and gives estimates of future national trends in volume of illness and medical care in an aging population. The data are based on the National Health Survey of 1935-36, supplemented by the morbidity studies of the Eastern Health District of Baltimore during the period 1938-43.

In the general population sampled, the annual case rate for chronic disabling lllness was approximately one-fourth the rate found among persons aged 65 and over. For the average person in the older group the period of disability from chronic illness during the year was more than four times as long as that experienced by the average person in the general population.

The so-called degenerattve diseases (mainly cardiovascular-renal disorders) are responsible for nearly one-third of the annual disability rates among the older age group, but account for less than 10 percent of the rate among the general population. Among those aged 65 and over, heart diseases head the list of 10 leading causes of disabling lliness and of days lost because of disability.

\section{Future Medical Care Needs}

Projecting these findings into the future, the number of disabling illnesses lasting seven consecutive days or longer may be about 25 percent higher in 1860 , and more than 40 percent higher by 1975 . Days lost annually from disability will rise 30 to 40 percent by 1960 and even higher by 1975 . As a result of both increase in population and increase in the number and proportion of the aged, the future thus will bring incrensing demands for the services of physlcians, hospitals, and nurses.

In 1835, physicians' services for persons aged 65 and over with cardiovascular-renal conditions totaled 7.3 million visits annually. If the same rate of visits is applied to the 1975 population of the United States, the comparable annual total may reach 18.7 million visits. In 1975 , more than 25,000 hospital beds will be needed for these conditions alone by persons aged 65 and over, on the basis of use in 1935. In that year, about 10,000 beds were used for cardiovascular-renal disorders among this age group.

Advances in medical knowledge and techniques, changes in the incidence, prevalence, and severity of illness, and economic factors that may alter earlier patterns of utilization of medical and other health services may well require modification of these predictions. Despite these qualifications, a few conclasions seem inescapable. Larger numbers of people (especially women) will live to an age in which their health status will require expanded resources to meet their needs for services of physicians, nurses, and other health personnel, and for hospital care. Increasingly, medical, hospital, and nursing serrices will be concentrated on the chronic diseases. Control of these diseases would greatly reduce not only the time lost from disability but also the patient load on hospitals, nurses, and physicians.

\section{Organized Community Planning for Old Age}

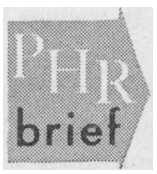

By PHILIP W. SWARTZ, Executive Secretary, Community Council of Bridgeport and Eastern Fairfield County, Conn.

To what extent are American communities utilizing and applying present knowledge concerning gerontology to serve the older portion of the population? A questionnaire survey yielded responses from 155 community areas, with over 72 percent of all areas of 75,000 or more listing an organization engaged in social planning. This represents 44 States. An analysis of some of the responses follows.

\section{Questions and Responses}

"Do you have a committee in your community concerned with over-all planning for old age?" About onethird of the communities had operating committees and an additional one-sixth had plans for formation of committees. Middle-sized cities showed greatest activity ; cities with over $1,000,000$ population had only a 75-percent coverage; the lowest rate was found in cities of smallest size. Although most communities had one or more services, many have been operating without much change for a long period.

"What specialized programs and facllities have been developed in your community?" The largest number of community areas were engaged in recreation. Following, in order, were homes for the aged, educational programs, hospitals, special and counseling services, and employment and vocational advice. Only. six community areas mentioned housing to serve the needs of the aging.

"Who pays for what?" Of the 485 facilities and programs sponsored in 137 urban areas, 32.5 percent were operated by voluntary agencies; 28.6 percent were tax supported ; 16.7 percent were operated by religious bodies; 12.2 percent, by clubs or independent organizations; 4.5 percent, by member payınents; 4.5 percent, by schools; and 1.4 percent, by commercial husinesses.

The greatest community needs were listed in order of importance: housing and living arrangements, employment services, public rellef, visiting homemaker service.

"What difficulty is encountered by old people in obtaining emplorment in a normal labor market?" Diffculty increased with uge in both normal and defense labor markets, but to a lesser degree in the defense labor markets.

"What are the chief attitudes in your community toward old age, and what changes have occurred orer the past decade?" In a considerable number of areas, the thinking of the community and the attitudes of employers are now favorably disposed toward considering the older person as an individual. Many areas felt that the development of retirement plans and insurance requirements have helped to withhold application of some favorable attitudes in the employment market. Considerable progress made during World War II in the attitudes of employers has been maintained. 


\section{Evaluation}

A large number of communities have made considerable progress and some are displaying imagination and interest pointing toward major contributions. There are fewer bright spots where frontier and experimental services are being sponsored. A great lag exists between newer knowledge that has been developed on basic needs and application of such findings. Many programs are not suited to community needs. Great gaps exlst throughout the country, with housing a pressing need for all sections and in all areas. Improvements are essential in services for employment, health, specialized home care, personal counseling and adequate financial allowances for the dependent and partially dependent.

Finally, the investigation emphasizes that society has in no substantial way recognized the responsibility for meeting psychosocial needs that accompany the later years of life.

The full text of this paper is scheduled to appear in the JanuaryFebruary 1952 issue of Geriatrics.

\section{Housing of the Aged, 1950}

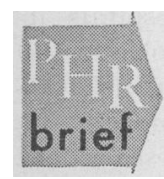

BY LEONARD S. SILK, LL. B., Division of Housing Research, Housing and Home Finance Agency, Washington, D. C.

To date there has been a lack of a factual, orer-all picture of the existing housing characteristics and living arrangements of older people in the United States. The absence of such information has made it virtually impossible to qualify the housing needs of the aged for the Nation as a whole and to relate these needs to those of the rest of the population. The tendency has been to concentrate research on the welfare and medical aspects of housing, with too little attention given to the economic dimensions of the problem.

In the hope of remedying this situation, the Housing and Home Finance Agency has analyzed special tabulations of data drawn from the housing census of 1950. The survey, based on preliminary data, of a national 1-in-a-1,000 sample of the American population, covers the housing circumstances only of those aged persons who are heads of households, not those who live as dependents in families headed by younger persons.

With the aged defined simply as those over 65, the total number of such persons living in urban or rural nonfarm housing in 1950 was 10,570,000. It is estimated that at least $\mathbf{8 0}$ percent of all persons over 65 maintained independent households.

\section{Home Ownership}

The percentage of home ownership is higher among persons over 65 (68.2 percent) who are heads of families than for the general population (53 percent). However, older people own less valuable structures than do the population generally. Those older people who are renters pay lower rents than the rest of the population. Persons over 65 tend to have larger dwelling units than the younger population. But more households headed by older persons were small-two persons or less. As a result, there is far less overcrowding among households headed by older persons than for the population as a whole. On the other hand, the condition of the housing in which the older groups live is below average.

\section{Characteristics of Housing}

In general, the aged tend to occupy relatively more very low-rent dwelling units and low-value structures, and their housing is relatively more dilapidated and deficient in plumbing facilities. However, overcrowding is not a particular problem for older people. Housing for older people is shaped and characterized by the following: The aged receive less income, have smaller families, and occupy older dwellings in older neighborhoods than do other groups in the popalation.

The full text of this paper is scheduled to appear in a forthcoming issue of the Journal of Gerontology.

\section{Geriatrics: General Considerations}

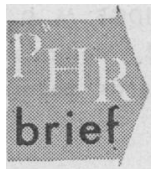

BY MALFORD W. THEWLIS, M. D., Thewlis Clinic, Wokefield, R. I.

Favorable economic conditions, better hygiene, medical and surgical advances-especially the use of antibiotic substances-have increased the national life span. There are many problems facing us in caring for the older population. There are fewer nurses and fewer hospital beds. At the same time there is an increase in chronic illness, especially since people live longer.

Perhaps the best approach to the problem is to keep the aged popalation ambulatory as much as possible. This can be accomplished by better hygiene, improved nutrition, and adequate housing.

The physician can keep older patients active and working by treating them in his office. Once they get into an institution they are likely to remain there. Already there are postgraduate courses in practical office procedures for physicians. More efficiency will enable the physician to treat these patients in his office or in their homes, and thus relieve the congestion in institutions. Merely instructing the patients on proper nutrition helps them to ward off lllness. It is amazing how much better many older people feel when they have an adequate intake of ascorbic acid, calcium, and proteins.

Many problems of advancing years must be solved by clinicians. They deal with the patients under conditions as they exist. Their experience enables them to guide social workers, physiotherapists, hospital superintendents, and others active in the field of geriatrics. On the other hand, preclinical medicine must be increasingly practiced by the medical profession.

The full text of this paper appeared in Medical Times 79: 737-738 (December 1951). 


\section{Medical and Social Problems in England}

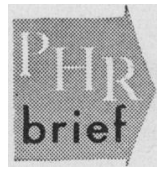

BY R. E. TUNBRIDGE, M. D. Department of Medicine, University of Leeds, Leeds, England

One of the features of the present century has been the change in the age composition of the population in almost every country. In the United Kingdom today, approximately 1 in 7.5, or almost 14 percent of the population, are of pensionable age, that is, men over 65 and women over 60 years of age. Between onefifth and one-sixth of the population will be of pensionable age by 1980 . Taking into account that one-fifth of the population will be composed of children under 15 and that many married women will be outside the labor force, it would appear that less than 50 percent of the population will have to support the entire population.

\section{Pension Plans}

Provision for retirement is from two sources, pension schemes where the amount of pension is based upon previous earnings, and the flat rate which is available to all other insured but not self-employed workers. In addition, old age pensions are available to all people over 70 provided their income does not exceed two pounds $(\$ 6)$ per week. The cost of the limited pension scheme now takes more than one-tenth of the national budget. In 30 years, if money retains its present value, the pensions will cost at least onefifth of the national budget. These assessments do not take account of the cost of other social services for the aged.

Increased methods of production may help to remedy the situation, but the obvious solution is to abolish full retirement at the present early age of 65 for men and 60 for women and to encourage part-time work as long as possible. This is desirable from a medicosocial as well as an economic viewpoint because early retirement frequently leads to a sense of not being wanted, uselessness, and loneliness, with serious consequences to the health and happiness of the retired person.

\section{Medical Care}

The change in the age composition raises many fundamental medical problems. It cannot be too often stated that disease in the elderly is not invariably chronic illness. Several recent surveys in the United Kingdom have shown that the common disorders in persons over 70 requiring hospitalization are mental disorders, arthritides, vascular degeneration, incontinence, and bronchitis.

Minor medical maladies and social factors, if not given sufficient attention, can hasten decline. Although sickness in the elderly does not exhibit entirely new disease forms, the reaction of the older patient to illness does provide many medical and social problems. It is often impossible to separate the medical from the social problems, and both must be assessed and adequately met. Adequate care for the aging thus demands a reorientation in medical teaching among doctors and nurses.

\section{Intensive Home Care Of the Chronically III}

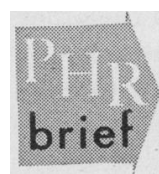

BY LOUIS UDELL, M. D. Medical Director, Intensive Home Care Plan, visiting Nurse Society of Philadelphia

Because of the limited number of hospital beds available and the very apparent increase in the incidence of chronic diseases, especially in the aged group, the problem of caring for these patients is becoming more acute. Home care seems to be the answer for many persons who do not need active specialized care.

Philadelphia has had an intensive home care plan for the chronically ill in operation since April 1949. It was developed in response to organized community demand to determine whether medical and supportive services for chronically ill patients in their own homes and under the care of their own visiting phy- sician would lead to maximum improvement at less expense than through hospital and institutional care. During the 2 years it has been in operation (in a section of the city with a population of 325,000 ), the plan has cared for 110 patients, about half of whom were over 65 years of age. Services have been offered on a visiting basis at a frequency determined by the need and have been coordinated by a community public health nursing association. These services include medical, nursing, physical therapy, occupational therapy, nutrition, speech training, and housekeeping care, supported by social case work and mental health consultation. The team approach has been used throughout with careful admission review and regular progress conferences. Referrals have come from all hospitals and a large number of private physicians in the area.

This plan, though patterned after the Montefiore Hospital home care plan, differs from it mainly in (1) control of the patient, (2) home conditions, and (3) administration. Patients remain under the control of their own private physicians, rather than under the direct care of the hospital. Unlike the hospital plans, ideal home conditions do not enter into the decision to accept a patient. Finally, the hospitals in the area have no direct voice in the administration of the plan, although they do refer their chronically ill patients and provide necessary laboratory or $\mathrm{X}$-ray services, or medical and surgical consultation, on a fee basis.

The net cost of the plan for two and a quarter years has been \$25,439.75. It has cost the community approximately $\$ 3$ each patient-day.

The reaction of the hospitals and the private physicians in the area to the plan has been very favorable. Moreover, the patients and their families have benefited considerably. Improvements have been noted in conditions formerly believed to be static or hopeless.

This program is suggested as one approach to the problem of care for older persons with chronic illness who wish to remain at home. Consideration of the organizational pat- 
tern, the relationships involved, and the costs of promotion and operation leads to the conclusion that such a plan can be repeated in a wide variety of communities.

\section{Needs for Economic Security in Old Age}

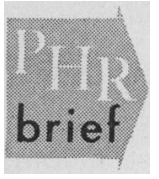

By EDWIN E. WITTE, Ph. D., Chairman, Department of Economics, University of Wisconsin

Two main points are made as antidotes to popular impressions: First, adequate economic means, although not all that is needed, are essential for a happy old age. Second, many different approaches are needed to insure adequate income in old age. Specifically, on the latter point, increasing employment opportunities for older people are not a cure-all for the economic problems.

\section{Economic Problems}

Increased attention to noneconomic problems which the gerontological movement has produced may minimize the importance of economic issues. Although this recent interest is to the good, it may obscure the important truths that many older people lack economic means for decent existence. Prolonging life by conquering disease does not of itself solve the problem of how people will live. For the great majority of people, old age is a time of reduced income and, for many, complete cessation of earnings.

Although many costs decrease in the older years, some increase with age, notably costs of medical and related care. Also, old age is becoming a progressively longer pe- riod for many people-average life expectancy for men at 65 is over 13 years and for women, about 3 years longer, more than one-fourth as long as the so-called productive period of life.

Just as for most people, employment is the best way to provide economic security for older persons. But, many older people cannot work full time or at all, and those who can work cannot be readily fitted into new jobs. Nearly half cannot work by reason of physical incapacity. The present enthusiasm for increased employment of older people is most laudable, but the entire problem of economic support cannot be answered by finding employment for older workers. Women now exceed men in this age group and their percentage is rapidly increasing. The proportion of older women workers has increased but is still below 10 percent. Even maintaining the present percentage of men who are gainfully occupied-45 percent-will necessitate the employment of many more older people, as their number is increasing so rapidly.

\section{Support for Older People}

We know very little about how older people actually get their livelihood. It is clear that many older people have to live very skimpily. We must find out why some older people are in need while others are getting along very well economically. Two factors seem mainly to account for this difference : earnings received before age 65, and employment or lack of employment after 65. Back of these are other reasons for want in old age : unemployment, long serious illness, disabilities, loss of savings and their declining value.

We also know little about the savings of older people. Although savings have greatly increased during the last decade, certain forms of savings have greatly shrunk in value.

We should also know more about the extent of aid from children and the significance of industrial pensions which have been very much in the limelight in recent years.

There is great need for more research and information, but likewise for acquainting the public with facts already known and presenting these facts in the proper perspective. Among these are the defects in the present Government systems: the old-age assistance program anomalously gives older people larger payments than are provided on the average under the contributory insurance system.

\section{Conclusions}

In stressing defects in present programs for economic security, progress made in the last two decades must not be overlooked. Older people are better off economically than they were during the depression and, quite likely, than during the prosperous twenties. But these programs have hardly kept up with changing price levels and improvements are necessary.

Increased attention must be given to social security and to the economic aspects of the aging population. The prevailing ignorance on these aspects is astounding in view of the immense amount of discussion. This may be one consequence of the gerontological movement. It may lull people into thinking that the economic problems of old age have been solved if only the employment opportunities of older people are increased. This would be most unfortunate, because it is clearly false.

\section{Scheduled for Early Publication}

The Mental Hygiene of Aging. By Paul V. L $\overrightarrow{\mathrm{emk}}$ au.

Hospital Beds in the United States. The unmet bed needs, as reflected by comparing 1951 with 1948 data, are reported.

Lead Poisoning in Young Children. Prevention methods for local health departments are discussed by Huntington Williams, Emanuel Kaplan, Charles E. Couchman, and R. R. Sayers.

Effect of Radioactive Materials in Environmental Health. Radiation hazards are explained by Conrad P. Straub. 